\title{
Editorial - Special Collection Gender Justice, Health and Human Development
}

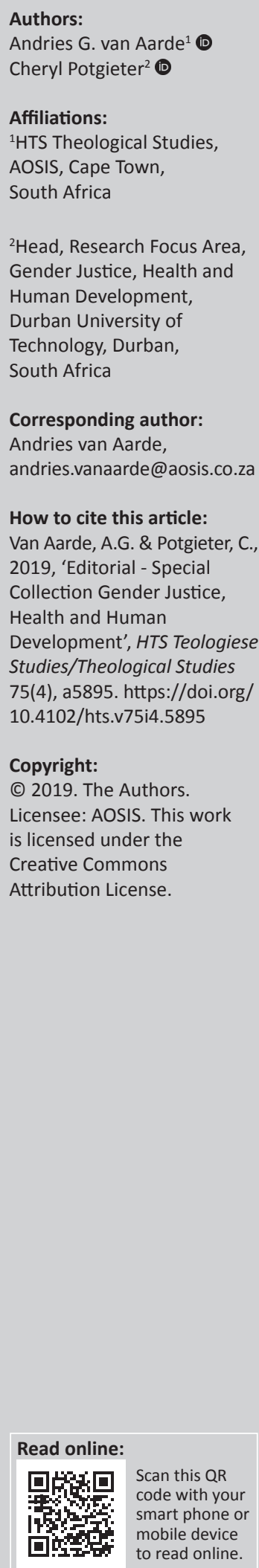

The invitation by the editor-in-chief to guest edit a subsection of the special collection was enthusiastically responded to and welcomed by the Durban University of Technology (DUT) new research focus area on Gender Justice, Health and Human Development. This indicates that HTS is indeed interdisciplinary in supporting research and knowledge production. We were allocated a few spaces for articles in the section and the regular process of submission and blind review followed.

The focus area supports and encourages postgraduate students and early career academics, especially those who have recently completed master's and doctoral degrees to publish their work.

The articles in the section focussing on mainstreaming gender and gender challenges in education and the public sector reflect the work of recently emerging scholars who are attached to the research focus area.

The research initiative aims to be a knowledge hub for postgraduate students and emerging and established scholars and academics to research, produce knowledge as well as to influence policy and interventions. The primary disciplines of the students and academics who are currently working in this focus area represent fields such as education, taxation and governance, theology, psychology, management, development studies and political studies. However, the common thread related to their work is the acknowledgment and understanding that gender injustice is a barrier to meeting any of the sustainable developmental goals.

Amartya Sen's concept of 'missing' women can be extended to the South African society in a number of ways. Amartya Sen's argument was that if women had been born male many more would have been alive, not dead and thus 'missing'. Essentially, fundamental to them being missing is gender injustices which impacted their health and development.

The South African society has a very high level of gender-based violence and many women are 'missing' because they are killed by their intimate partners. In addition, many young black girls are poverty stricken as is indicated in one of the articles in this collection, and they go 'missing' from the education system. The focus area has a commitment to support and mentor female academics and especially black female academics into the professoriate. However, we are aware that supporting women in the academic spaces has to be part of a broader intervention that includes addressing the societal gender injustices through research, interventions and working and partnering with communities.

At this point there are various and many understandings of feminism, as well as approaches to development. The intellectual hub will participate in and facilitate many debates and engagements that will undoubtedly include what we understand by feminism, gender justice and development.

The Gender Justice, Health and Human Development focus area has, and will continue, to form partnerships locally, regionally and globally to engage in research, publications and conferences, addressing the issues that are important for building a world where women are not missing but present as full citizens. We are optimistic that in the next few years all our students would have graduated, published and committed for supporting others. Amartya Sen spoke about the importance of building capacity if we need increased capability. The articles in this section by emerging academics are an attempt towards building capacity to ensure that there are capabilities and knowledge production and dissemination to ensure Gender Justice, Health and Human Development.

Note: Special Collection Gender Justice, Health and Human Development, sub-edited by Cheryl Potgieter (Durban University of Technology). 